\section{6 OPEN ACCESS}

\title{
Physical health and gender as risk factors for usage of services for mental illness
}

\author{
Flora I Matheson, ${ }^{1,2,3}$ Katherine L W Smith, ${ }^{1}$ Ghazal S Fazli, ${ }^{1}$ Rahim Moineddin, ${ }^{2,4}$ \\ James R Dunn, ${ }^{1,2,5}$ Richard H Glazier ${ }^{1,2,3,4,6}$
}

${ }^{1}$ Centre for Research on Inner City Health at The Keenan Research Centre in the Li Ka Shing Knowledge Institute of St. Michael's Hospital, Toronto, Ontario, Canada

${ }^{2}$ Institute for Clinical Evaluative Sciences, Toronto, Ontario, Canada

${ }^{3}$ Dalla Lana School of Public Health, University of Toronto Toronto, Ontario, Canada ${ }^{4}$ Department of Family and Community Medicine,

University of Toronto, Toronto, Ontario, Canada

${ }^{5}$ Department of Health, Aging and Society, McMaster University, Ontario, Canada ${ }^{6}$ Department of Family and Community Medicine, St. Michael's Hospital, Toronto, Ontario, Canada

\section{Correspondence to}

Dr Flora I Matheson, Centre for Research on Inner City Health, 30 Bond Street, St. Michael's Hospital, Toronto, ON, Canada M5B 1W8; mathesonf@smh.ca

Received 13 January 2014 Revised 8 May 2014 Accepted 27 May 2014 Published Online First 26 June 2014
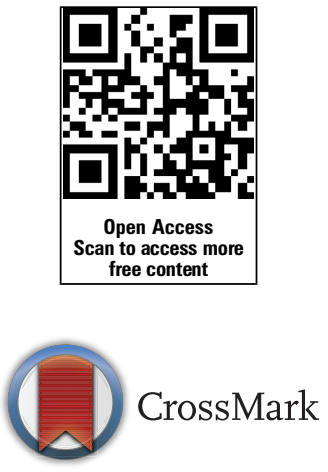

To cite: Matheson Fl, Smith KLW, Fazli GS, et al. $J$ Epidemiol Community Health 2014;68:971-978.

\section{ABSTRACT}

Background People with comorbid mental and physical illness (PI) experience worse health, inadequate care and increased mortality relative to those without mental illness (MI). The role of gender in this relationship is not fully understood. This study examined gender differences in onset of mental health service usage among people with physical illness (COPD, asthma, hypertension and type II diabetes) compared with a control cohort.

Methods We used a unique linked dataset consisting of the 2000-2001 Canadian Community Health Survey and medical records ( $n=17050)$ to examine risk of onset of $\mathrm{Ml}$ among those with and without $\mathrm{Pl}$ among Ontario residents (18-74 years old) over a 10-year period (2002-2011). Adjusted COX proportional survival analysis was conducted.

Results Unadjusted use of MI medical services in the $\mathrm{PI}$ cohort was $55.6 \%$ among women and $44.7 \%$ ( $p=0.0001$ ) among men; among controls $48.1 \%$ of the women and $36.7 \%$ of the men used MI medical services $(p=0.0001)$. The relative risk of usage among women in the PI group relative to controls was 1.16. Among men, the relative risk was 1.22 . Women were 1.45 times more likely to use MI medical services relative to men $(\mathrm{HR}=1.45, \mathrm{Cl} 1.35$ to 1.55$)$. Respondents in the $\mathrm{PI}$ cohort were 1.32 times more likely to use MI medical services ( $H R=1.32, \mathrm{Cl} 1.23$ to 1.42 ) relative to controls. Women in the PI cohort used MI medical services 6.4 months earlier than PI males ( $p=0.0059$ ). In the adjusted model, women with PI were most likely to use MI medical services, followed by women controls, men with $\mathrm{Pl}$ and men controls. There was no significant interaction between gender and PI cohort.

Conclusions Further, gender-based research focusing on onset of usage of $\mathrm{Ml}$ services among those with and without chronic health problems will enable better understanding of gender-based health disparities to improve healthcare quality, delivery and public health policy.

\section{INTRODUCTION}

Chronic diseases represent the leading cause of death and disability and a major challenge facing today's healthcare system. ${ }^{1}$ Approximately half of Canadians and Americans suffer from a chronic illness. ${ }^{1} 2$ Comorbidity of chronic diseases is increasingly common among adults and is more prevalent with advancing age. For example, $13 \%$ of Canadians aged $20-39$ years, $71 \%$ of those aged $60-79$ years, and $82 \%$ of those 80 years and older, report multiple health problems. ${ }^{3}$

Individuals with comorbid mental and physical illness experience worse outcomes, inadequate care and increased mortality relative to those without mental illness. ${ }^{4-6}$ Mental disorder is elevated in people with any chronic disease, ${ }^{7-9}$ specifically among those with diabetes, ${ }^{10}$ chronic obstructive pulmonary disorder (COPD), ${ }^{11}$ and asthma. ${ }^{12}$ Patten ${ }^{13}$ found that the annual cumulative incidence of depression was higher among individuals with any long-term medical condition relative to those without such problems. Other research has found that patients with COPD were significantly more likely to be diagnosed with depression than people with diabetes or controls. ${ }^{14}$

Various pathways between chronic pain and depression have been postulated. People with multiple pains experience more depression than those with a single pain source. ${ }^{15}$ Pain can affect sleep patterns and increase emotional distress. The experience of frequent pain might also be a signal for depression. ${ }^{16}$ Disability from chronic illness can also be a risk factor for depression. ${ }^{17}$ Other debilitative effects of some illnesses (eg, changes in physical appearance, decreased functioning) can heighten the risk of depression. ${ }^{78}$ These pathways may also differ depending on the type of physical illness experienced.

A small number of epidemiological studies have investigated gender differences in onset of mental illness secondary to a chronic physical illness. One study showed higher prevalence of mental disorder/ distress among women with chronic disease relative to men. ${ }^{7}$ Schneider $e t a l^{19}$ found an increased risk of depression among patients with COPD. He also found that lifetime prevalence of depression was twofold among women compared to men. With COPD duration, this condition was further exacerbated in women. Moreover, his findings showed that more patients with depression and COPD died within a year of the index date; notably, the gender difference in mortality was greater among men. ${ }^{19} \mathrm{~A}$ national health study on asthma showed that gender differences in depression decrease with advancing age, but depression remains higher among those with asthma relative to those without the illness. ${ }^{8}$ Patten found that hypertension was associated with an elevated risk of depression, but only among men. ${ }^{20}$ Given the equivocal nature of the findings, current evidence does not provide a clear picture of the gendered nature of the relationship between mental and physical disorders.

Using a unique dataset comprised of medical and national survey data, the primary objective of this cohort study was to examine: (1) whether gender was an important risk factor when considering whether those with baseline physical illness (PIasthma, chronic obstructive pulmonary disease, 
type II diabetes and hypertension) were more likely to use medical services for mental illness (MI) relative to a comparison group without baseline PI and (2) whether there are gender differences in onset of usage of medical services for MI.

\section{METHODS}

Ethical approval was obtained from St Michael's Hospital and Sunnybrook Health Sciences Centre Research Ethics Review Boards. The study was conducted in Ontario, Canada where there is universal medical coverage. All permanent residents of Ontario are eligible for healthcare without deductibles or copayments. ${ }^{21}$ Adults were eligible for inclusion in this study if they had a valid health card number at the index date of the study (2000-2001) and the date of death occurred after the study start date. The methodology adopted in this study is similarly described in a paper by the same research team in their investigation of the relationship between baseline MI and the onset of PI. ${ }^{22}$

\section{Data sources}

The Institute for Clinical Evaluative Sciences (ICES) provided the data for this study. Physical and mental health data and other health indicators were obtained from the Ontario Linking file of the Canadian Community Health Survey (CCHS) 1.1 (cycle 2000-2001). ${ }^{23}$ The CCHS is a nationally representative and cross-sectional survey which collected data from noninstitutionalised Canadians over the age of 12 years. Respondents in the linking file agreed to have their responses linked to medical data for research purposes. The response rate was $82.0 \%$ (39 278), and 90.8\% agreed to linkage; 92\% of those who agreed were successfully linked providing a sample of 32848 . We excluded $5 \%$ of cases with missing values on variables other than income, and restricted the sample to those aged 18-74 years. The final sample was 17050 (6213 in the physical illness cohort and 10837 in the control cohort).

Supplementary mental and physical illness data were obtained from medical records. Ontario Health Insurance Plan (OHIP) data contains physician visits and procedure claims which include service and diagnostic codes, fees for service provided, and date of service. The Canadian Institutes for Health Information (CIHI) Discharge Abstract Database (DAD) contains up to 16 diagnoses and 12 procedures for acute care hospitalisations and day procedures across Ontario. The Ontario Mental Health Reporting System (OMHRS) provides data on patients in adult designated inpatient mental health beds, including beds in General, Provincial Psychiatric, and Specialty Psychiatric facilities. We determined eligibility for health services and death date from the Registered Person Data Base (RPDB); Ontario's healthcare registry that provides information on age, sex, postal code, eligibility and death data.

\section{Physical illness cohort}

The physical illness (PI) cohort was defined using the CCHS and medical records, and included respondents in the linked CCHS who self-reported at least one PI (asthma, COPD, hypertension, or type II diabetes). People not self-reporting PI, but who met the criteria for any of these conditions in the validated medical registries (eg, a respondent saw a physician for physical health reasons) were also included in the PI cohort $(n=6213)$, and were subject to the same inclusion criteria as respondents in the CCHS. Similar to our previous study, ${ }^{22}$ we used four disease-specific ICES-validated cohort databases to identify physical illness in the 10 -year follow-up period.

Patient records for those with any of the four physical health diagnoses are retained in disease-specific registries at ICES.
People with asthma had one hospital admission or two OHIP claims with asthma diagnosis within 2 years (sensitivity: $84 \%$; specificity: $76 \%) .{ }^{24}$ Those with COPD had one COPD diagnosis in OHIP or CIHI-DAD (sensitivity: $85 \%$; specificity: $78.4 \%$ ). ${ }^{25}$ Hypertensive patients had one hospital admission with a hypertension diagnosis, or an OHIP claim with a hypertension diagnosis followed within 2 years by either an OHIP claim or a hospital admission with a hypertension diagnosis (sensitivity: 72\%; specificity: 95\%). ${ }^{26}$ People with type II diabetes had at least one hospitalisation or at least two claims for physicians' services within 2 years (sensitivity: $86 \%$; specificity: $97 \%$ ). ${ }^{27}$ The administrative data was assessed for accuracy using abstracted medical records (primary care charts). In the case of hypertension, additional validation was conducted using selfreported survey data from a national census.

To ensure that MI usage did not occur prior to or concurrently with PI, we excluded anyone with the following: (1) selfreported depression, (2) consulted a mental health professional, (3) felt they needed treatment for an emotional problem, but did not receive care, (4) who had physician or ER visits or hospitalisations for mental health reasons during the two years prior to the CCHS interview. In the CCHS, self-reported depression was assessed using the Composite International Diagnostic Interview Short Form for Major Depression (CIDI-SFMD). The CIDI-SF is a validated epidemiological tool to identify depression used in non-clinical settings. In this study, major depression was defined as those reporting four or more depressive symptoms; meaning that $81.25 \%$ of cases meeting these criteria would have major depression according to the full CIDI. ${ }^{28}$ The prevalence of PI conditions in the CCHS was as follows: asthma (9.0\%); COPD (4.2\%); type II diabetes $(5.5 \%)$; hypertension (16.6\%).

A control cohort $(n=10837)$ included respondents who did not meet the criteria for inclusion in the PI cohort, and those who did not have a MI based on self-report and medical data.

\section{Mental illness service usage}

Onset of MI usage in the 10-year follow-period was defined using a combination of service and diagnostic codes used by Ontario physicians. When mental health services are provided, physicians may assign either a mental health-specific service code (when a visit exceeds $20 \mathrm{~min}$ in length) or a general service code (for shorter visits), which is a 3-digit shortened version of the codes provided in the International Classification of Diseases and reflects the most responsible reason for any visit. $^{29} 30$

Diagnostic codes for mental health usage were derived from a validation paper. ${ }^{29}$ The list of conditions includes diagnostic codes for psychotic disorders, non-psychotic disorders (including anxiety and depression), substance abuse disorders and social problems. The study compared patient surveys and administrative claims, and established that claims data are reasonable to identify patients who had received mental healthcare (sensitivity: 80.7\%; specificity: 90.7\%). Mental illness usage was defined as at least one visit to a physician or specialist for mental health reasons. The event or first episode was defined as the first usage for any of the co-occurring health conditions in either OMHRS, OHIP or the DAD.

\section{Health indicators}

We controlled for several health indicators known to be associated with gender differences in health ${ }^{31}{ }^{32}$ : socioeconomic and demographic characteristics (highest level of education attainment, annual household income, age, marital status, 
ethnoracial origin); and health behaviours (perceived stress and activity level, smoking and drinking status). Leisure-time physical activity was calculated based on the frequency and duration of each activity within the 3 months prior to being surveyed (energy expenditure-EE) and its value of metabolic energy cost. We used predefined categories from Statistics Canada for physically inactive, moderately active, and active, ${ }^{23}$ combining moderately active and active for this analysis. Heavy drinking was defined as 14 plus weekly drinks for men and 10 plus weekly drinks for women. Current smokers were those who reported being daily or occasional smokers. Respondents were classified as having 'high and low stress' based on their responses to the question: 'Thinking about the amount of stress in your life, would you say that most days are (not at all stressful, not very stressful, a bit stressful, quite a bit stressful, or extremely stressful)?' High stress reflected responses of 'quite a bit stressful' or 'extremely stressful.' The remaining responses were considered 'low stress.'

We adjusted for disease comorbidity using three measures: restriction of activities, Resource Utilization Bands (RUBs) and Aggregated Diagnosis Groups (ADGs). RUBs and ADGs were generated using The Johns Hopkins Adjusted Clinical Groups (ACG) System and represent morbidity burden of populations. ${ }^{33}$ RUBs are constructed using age, sex and mixtures of diagnoses associated with expected intensity of resource use with values categorised as low $(0,1)$, intermediate $(2$ and 3$)$, and high $(4,5)$ burden of illness on the healthcare system. ADGs represent a collection of diagnostic codes similar in severity and expected persistence over time. ADGs reflect comorbidity and additional health burden on top of that reflected by RUBS and were categorised as low (0-1), moderate (2-5) and high (6-34). Both were calculated in the 2 years prior to the CCHS interview. Restriction of activities was self-reported: 'Do you have any difficulty hearing, seeing, communicating, walking, climbing stairs, bending, learning or doing any similar activities?' and coded sometimes, often and never.

\section{Statistical approach}

First, we compared baseline characteristics of the PI and control cohorts. We provide unweighted sample numbers and weighted proportions generated using the survey weights provided by Statistics Canada. ${ }^{34}$

Cox proportional hazard regression was used to estimate the effect of gender and PI status on MI while adjusting for the effects of other covariates. This models the length of time until the occurrence of an event-onset of MI-during the 10-year follow-up. Survival curves for time to first occurrence of MI were obtained with the Kaplan-Meier method. Tests for proportionality and interactions with time were not significant (eg, plotted survival function vs $\log$-log survival function; tests for interactions of each variable with time). Data publication guidelines of Statistics Canada were followed throughout the analysis. SAS V.9.2 (SAS Institute, Cary, North Carolina, USA) was used for data manipulation and statistical analysis.

\section{RESULTS}

Table 1 shows the distribution of the sample by covariates. The PI cohort had an equal gender distribution; there were slightly more men than women in the control cohort (54.4\%). More respondents in the PI cohort reported no high school diploma $(25.4 \%)$ relative to those in the control group (12.7\%). Twice as many respondents in the PI cohort (8.7\%) reported income
Table 1 Descriptive statistics for the physical illness and control cohorts by sociodemographic characteristics and health indicators

\begin{tabular}{|c|c|c|}
\hline & \multicolumn{2}{|c|}{ Sample characteristics $(\%, \mathrm{~N})$} \\
\hline & $\begin{array}{l}\text { Physical illness } \\
\text { cohort (6213) }\end{array}$ & $\begin{array}{l}\text { Control cohort } \\
(n=10837)\end{array}$ \\
\hline \multicolumn{3}{|l|}{ Gender } \\
\hline Female & $50.0(3273)$ & $45.6(5235)$ \\
\hline Male & $50.0(2940)$ & $54.4(5602)$ \\
\hline \multicolumn{3}{|l|}{ Age group-years } \\
\hline $18-29$ & $12.8(673)$ & $26.6(2494)$ \\
\hline $30-39$ & $13.8(743)$ & $26.6(2816)$ \\
\hline $40-49$ & $19.3(1054)$ & $24.9(2654)$ \\
\hline $50-59$ & $22.7(1319)$ & $12.8(1572)$ \\
\hline $60-74$ & $31.5(2424)$ & $9.1(1301)$ \\
\hline \multicolumn{3}{|l|}{ Educational attainment } \\
\hline No high school diploma & $25.4(1869)$ & $12.7(1762)$ \\
\hline High school diploma & $28.5(1710)$ & $34.2(3525)$ \\
\hline Post-secondary education & $46.1(2634)$ & $53.2(5550)$ \\
\hline \multicolumn{3}{|l|}{ Annual household income - CAN\$ } \\
\hline Under $\$ 20000$ & $8.7(785)$ & $4.4(703)$ \\
\hline$\$ 20000$ to $\$ 39000$ & $16.7(1295)$ & $12.3(1685)$ \\
\hline$\$ 40000$ to $\$ 59000$ & $16.5(1030)$ & $15.3(1822)$ \\
\hline$\$ 60000$ to $\$ 79000$ & $13.8(801)$ & 17.6 (1894) \\
\hline$\$ 80000+$ & $24.0(1089)$ & $32.1(2925)$ \\
\hline Missing & $20.4(1213)$ & $18.3(1808)$ \\
\hline \multicolumn{3}{|l|}{ Marital status } \\
\hline Separated/divorced/widowed & 12.9 (1239) & $7.2(1240)$ \\
\hline Single & $16.8(979)$ & $26.8(2721)$ \\
\hline Married/common-law & $70.2(3995)$ & $66.0(6876)$ \\
\hline \multicolumn{3}{|l|}{ Ethnoracial origin } \\
\hline White & $85.0(5817)$ & $82.9(9932)$ \\
\hline Others & 15.0 (396) & $17.1(905)$ \\
\hline \multicolumn{3}{|l|}{ Self-perceived stress } \\
\hline Moderate/high & $23.3(1388)$ & $20.5(2184)$ \\
\hline Low/none & 76.7 (4825) & $79.5(8653)$ \\
\hline \multicolumn{3}{|l|}{ Current smoker } \\
\hline Yes & $24.4(1565)$ & $26.6(3084)$ \\
\hline No & $75.6(4648)$ & $73.4(7753)$ \\
\hline \multicolumn{3}{|l|}{ Heavy drinker } \\
\hline Yes & $2.5(188)$ & $3.6(427)$ \\
\hline No & $97.5(6025)$ & $96.4(10410)$ \\
\hline \multicolumn{3}{|l|}{ Physical activity } \\
\hline Active & $19.5(1368)$ & $22.6(2714)$ \\
\hline Non-active & $80.5(4845)$ & $77.4(8123)$ \\
\hline \multicolumn{3}{|l|}{ Disability } \\
\hline Often & $14.2(1062)$ & $5.2(707)$ \\
\hline Some & $19.5(1347)$ & $11.1(1321)$ \\
\hline Never & $66.3(3804)$ & $83.7(8809)$ \\
\hline \multicolumn{3}{|l|}{ Rural } \\
\hline Yes & $16.5(1386)$ & $15.9(2427)$ \\
\hline No & $83.5(4827)$ & $84.1(8410)$ \\
\hline \multicolumn{3}{|l|}{ Aggregated Diagnosis Groups } \\
\hline Low (0-1) & $9.6(625)$ & $26.4(2991)$ \\
\hline Medium (2-5) & $50.2(3152)$ & $53.8(5837)$ \\
\hline High (6-34) & $40.2(2436)$ & $19.8(2009)$ \\
\hline \multicolumn{3}{|l|}{ Resource Utilization Bands } \\
\hline Low (0-1) & $6.9(416)$ & $22.6(2526)$ \\
\hline Medium (2) & $14.1(876)$ & 27.7 (2979) \\
\hline High (3) & $61.5(3725)$ & 41.5 (4474) \\
\hline Very High (4-5) & 17.5 (1196) & $8.1(858)$ \\
\hline
\end{tabular}


under CAN\$20 000 in comparison with controls (4.4\%). More people in the PI cohort were aged $50+$ years $(54.2 \%$ vs $21.9 \%$ ), and reported often or some activity restriction versus controls (33.7\% and 16.3, respectively), and higher morbidities relative to controls $(40.2 \%$ and $19.8 \% ; 79.0 \%$ and $49.6 \%$; respectively).

Overall, the prevalence of usage of health services for MI in the sample was $44.6 \%$ (41.9\% in the controls and 50.2\% in the PI cohort; $p=0.001)$. Half $(49.7 \%)$ the people in the control cohort reported having used medical services for a $\mathrm{MH}$ problem and PI at follow-up. Table 2 shows the percentage/number of respondents in each cohort that subsequently used medical services for MI by the end of the 10-year follow-up period (columns 2/3). More men and women in the PI cohort used services for a subsequent mental illness than their counterpart controls (women: $55.6 \%$ vs $48.1 \%$; men: $44.7 \%$ vs $36.7 \%$, respectively; $\mathrm{p}=0.0001)$. The relative risk $(\mathrm{RR})$ of usage among women in the PI group relative to women controls was 1.16 . The RR for men was 1.22. Respondents in the PI cohort consistently reported higher usage for MI than controls across all risk factors with at least a $10 \%$ or greater difference for several variables, including age, education, income, stress, disability and rural location.

The median onset of MI usage for the entire sample was 39.3 months. There was a modest difference in median onset of usage of medical services for MI between the PI (36.7 months or 3.05 years) and control (40.9 months or 3.41 years; $\mathrm{p}=0.0059$ ) cohorts. For men with PI, the median time to onset of usage for MI was 40.3 versus 45.6 months (3.4 years and 3.8 years, respectively; $\mathrm{p}=0.0059$ ) among controls. For women in the PI cohort, the median time to event was 33.9 versus 37.5 months among controls (2.8 and 3.1 years, respectively; $\mathrm{p}=0.0172$ ).

Based on bivariate logistic regressions (not shown), women were 1.45 times more likely to use medical services for MI compared with men $(\mathrm{HR}=1.45$, CI 1.35 to 1.55$)$. Respondents with a pre-existing PI were 1.32 times more likely to use medical services for $\mathrm{MI}(\mathrm{HR}=1.32$, CI 1.23 to 1.42$)$. Table 2 shows the adjusted HRs. Female $(\mathrm{HR}=1.28$, CI 1.19 to 1.37$)$ and preexisting PI $(\mathrm{HR}=1.14$, CI 1.05 to 1.23$)$ remain statistically significant after adjusting for other risk factors.

To further explore gender differences in risk of onset of usage of medical services for MI, we examined the adjusted probability of onset of the event by gender and cohort. As figure 1 shows, the probability of onset of usage of medical services for MI differed across the groups. While risk increased over time for all groups, women with PI were at greatest risk of onset of usage of medical services for MI, followed by women controls, men with PI and men controls. We also tested for an interaction between gender and PI status which was not significant ( $\mathrm{HR}=0.99$, CI 0.85 to 1.13$)$.

We conducted condition-specific cohort analyses to test if gender differences were masked by combining the physical illnesses. The gender by condition-specific cohort interactions were not significant (data not shown). The $\mathrm{p}$ values ranged from 0.31 for COPD to 0.96 for diabetes. In table 3, we present the HRs for the adjusted main effects models showing the HRs and $p$ values for female and cohort by each physical illness condition. The HRs for females were highly similar across the health conditions and to the combined HR shown in table 2 $(\mathrm{HR}=1.28)$. The condition-specific cohort HRs were also very similar to the combined HR $(\mathrm{HR}=1.14)$ in table 2; hypertension $(\mathrm{HR}=1.16$, CI 1.04 to 1.29$)$; COPD $(\mathrm{HR}=1.19$; $\mathrm{CI} 1.01$ to $1.37)$; diabetes $(\mathrm{HR}=0.96$, CI 0.81 to 1.12$)$; asthma $(\mathrm{HR}=1.16$, CI 1.04 to 1.28$)$.
We also conducted age-stratified analyses to determine if the gender effect was similar across age categories. We found that the gender differences were very similar across the younger age groups (18-29, 30-39, 4-49, 50-59) with HRs ranging from 1.26 to 1.39 . These are also similar to the HRs for females, shown in table $2(\mathrm{HR}=1.28)$. The gender difference was smaller and not statistically significant in the oldest age group (60-75 years).

\section{DISCUSSION}

The purpose of this study was two-fold: to examine whether people with chronic PI were more likely to begin using medical services for MI over a 10-year period; and, to examine if men and women with/without chronic PI have similar onset of usage of medical services for MI. Pre-existing, available, validated cohorts were used for all illnesses to ensure accuracy of diagnoses. At the end of the follow-up period, the overall prevalence of medical service usage for MI was $44.6 \%$ (controls: $41.9 \%$; PI cohort: $50.2 \%$ ).

The finding that PI was associated with greater risk of onset of usage of medical services for MI replicates earlier studies. $^{35}{ }^{36}$ In fact, we found that within the PI cohort, the onset of medical service usage for MI was 10\% higher among women. Women with PI also experienced slightly faster onset of medical service usage for MI than men with PI, about 6.4 months earlier. This suggests that within a 3 -year window (sample median of 39.3 months), women use mental health services 6 months earlier than men. A recent study examined onset of PI among men and women with MI and found that women developed PI about one year earlier than their male counterparts. $^{22}$ There are several potential implications of the gender difference in onset in medical service usage. If women begin to use services for mental illness 6 months earlier than men, this could be positive suggesting that women seek help earlier which could lead to better mental health outcomes; and, it might be perceived as negative for men who defer care for a number of months. Alternatively, it could mean that symptoms are worse among women, hence the reason they seek care earlier than men.

With further respect to gender differences, women were at greater risk of earlier onset of medical service usage for MI than men after adjusting for covariates in the survival model. This gender difference is reflected in previous research. ${ }^{7}{ }^{19}$ Risk of onset of usage of health services for MI over the 10-year period differed by gender-cohort groups. Women with PI were at greatest risk of usage of health services for MI, followed by women without PI. The next group most at risk was men with PI followed by men without PI. A previous study found that women with chronic somatic disease were at greater risk of developing a mental disorder than men. ${ }^{7}$ We also found that the gender difference in onset of mental health usage was similar for the younger age categories and was smaller and non-significant for older adults (60-75 years). This difference in help-seeking behaviour between older and younger adults seems to have some support in the literature. For example, MacKenzie et $a l^{37}$ examined attitudes in help-seeking and found that older adults had more positive attitudes towards help-seeking than young people.

Available research is not clear on the gendered nature of the relationship between PI and MI or on the nature of the onset of usage of medical services for MI. This study is unique, exploring onset of mental health service usage among those with and without physical illness who were also free of previous mental illness at the study start date. While one study found a higher 
Table 2 Adjusted HRs for onset of mental health utilisation for the physical illness and control cohorts adjusting for sociodemographic characteristics and health indicators $(n=17050)$

\begin{tabular}{|c|c|c|c|c|c|}
\hline & \multicolumn{2}{|c|}{ Onset of mental health utilisation $(\%, \mathrm{~N})$} & \multicolumn{3}{|c|}{ Model 1} \\
\hline & $\begin{array}{l}\text { Physical } \\
\text { Illness } \\
\text { Cohort } \\
(3075)\end{array}$ & $\begin{array}{l}\text { Control } \\
\text { Cohort } \\
(n=4507)\end{array}$ & HR & $95 \% \mathrm{Cl}$ & $\mathrm{p}$ Value \\
\hline \multicolumn{6}{|l|}{ Gender } \\
\hline Female & $55.6(1771)$ & 48.1 (2549) & 1.28 & (1.19 to 1.37$)$ & 0.001 \\
\hline Male & $44.7(1304)$ & 36.7 (1958) & 1.00 & & \\
\hline \multicolumn{6}{|l|}{ Physical illness cohort } \\
\hline Yes & - & - & 1.14 & (1.05 to 1.23$)$ & 0.001 \\
\hline No & - & - & 1.00 & & \\
\hline \multicolumn{6}{|l|}{ Age group - years } \\
\hline $18-29$ & $52.4(365)$ & $42.2(1089)$ & 1.16 & (1.00 to 1.33 ) & 0.039 \\
\hline $30-39$ & $52.9(404)$ & $43.4(1231)$ & 1.23 & (1.07 to 1.39$)$ & 0.001 \\
\hline $40-49$ & $51.9(548)$ & $40.7(1032)$ & 1.15 & (1.01 to 1.29$)$ & 0.023 \\
\hline $50-59$ & $48.0(620)$ & $42.3(641)$ & 1.10 & (0.96 to 1.22$)$ & 0.152 \\
\hline $60-74$ & $48.4(1138)$ & $39.9(514)$ & 1.00 & & \\
\hline \multicolumn{6}{|l|}{ Educational attainment } \\
\hline No high school diploma & 48.5 (932) & $41.1(742)$ & 0.97 & (0.86 to 1.07 ) & 0.518 \\
\hline High school diploma & $51.1(837)$ & $41.6(1433)$ & 0.98 & (0.90 to 1.05$)$ & 0.550 \\
\hline Postsecondary education & $50.4(1306)$ & $42.3(2332)$ & 1.00 & & \\
\hline \multicolumn{6}{|l|}{ Annual household income - CAN\$ } \\
\hline Under $\$ 20000$ & $49.6(390)$ & $43.0(313)$ & 1.04 & (0.88 to 1.21 ) & 0.594 \\
\hline$\$ 20000$ to $\$ 39000$ & $49.9(622)$ & $38.7(705)$ & 0.98 & (0.87 to 1.10$)$ & 0.783 \\
\hline$\$ 40000$ to $\$ 59000$ & $54.0(529)$ & $42.1(770)$ & 1.09 & (0.97 to 1.21$)$ & 0.118 \\
\hline$\$ 60000$ to $\$ 79000$ & $52.8(401)$ & $42.6(800)$ & 1.08 & (0.96 to 1.20$)$ & 0.185 \\
\hline Missing & $50.7(620)$ & $43.8(749)$ & 1.06 & (0.93 to 1.20$)$ & 0.323 \\
\hline$\$ 80000+$ & $45.8(513)$ & $41.4(1170)$ & 1.00 & & \\
\hline \multicolumn{6}{|l|}{ Marital status } \\
\hline Separated/divorced/widowed & $49.4(582)$ & $43.8(549)$ & 0.98 & (0.88 to 1.08$)$ & 0.672 \\
\hline Single & $48.2(474)$ & $41.4(1120)$ & 1.02 & (0.90 to 1.14 ) & 0.741 \\
\hline Married/common-law & $50.7(2019)$ & $42.0(2838)$ & 1.00 & & \\
\hline \multicolumn{6}{|l|}{ Ethnoracial origin } \\
\hline White & $50.4(2862)$ & $42.3(4138)$ & 1.17 & (1.02 to 1.33 ) & 0.019 \\
\hline Others & $48.7(213)$ & 39.9 (369) & 1.00 & & \\
\hline \multicolumn{6}{|l|}{ Self-perceived stress } \\
\hline Moderate/high & $56.8(791)$ & $44.4(1016)$ & 1.15 & (1.06 to 1.25$)$ & 0.001 \\
\hline Low/none & $48.1(2284)$ & $41.3(3491)$ & 1.00 & & \\
\hline \multicolumn{6}{|l|}{ Current smoker } \\
\hline Yes & $49.7(795)$ & $43.2(1310)$ & 1.12 & (1.03 to 1.21$)$ & 0.008 \\
\hline No & $50.2(2280)$ & $41.5(3197)$ & 1.00 & & \\
\hline \multicolumn{6}{|l|}{ Heavy drinker } \\
\hline Yes & $45.5(84)$ & $37.0(169)$ & 0.97 & (0.79 to 1.14 ) & 0.704 \\
\hline No & $50.2(2991)$ & $42.1(4338)$ & 1.00 & & \\
\hline \multicolumn{6}{|l|}{ Physical activity } \\
\hline Active & $48.0(668)$ & $42.1(1128)$ & 0.99 & (0.92 to 1.08$)$ & 0.977 \\
\hline Non-active & $50.6(2407)$ & 41.9 (3379) & 1.00 & & \\
\hline \multicolumn{6}{|l|}{ Disability } \\
\hline Often & $57.0(578)$ & $50.8(332)$ & 1.25 & (1.11 to 1.39 ) & 0.001 \\
\hline Some & $52.3(689)$ & $42.7(557)$ & 1.06 & (0.95 to 1.17 ) & 0.240 \\
\hline Never & $48.0(1808)$ & $41.3(3618)$ & 1.00 & & \\
\hline \multicolumn{6}{|l|}{ Rural } \\
\hline Yes & $49.4(653)$ & 37.9 (927) & 0.90 & (0.83 to 0.97$)$ & 0.012 \\
\hline No & $50.3(2422)$ & $42.7(3580)$ & 1.00 & & \\
\hline \multicolumn{6}{|l|}{ Aggregated diagnosis groups } \\
\hline High (6 to 34) & $59.4(1448)$ & $56.1(1155)$ & 2.05 & (1.68 to 2.42$)$ & 0.000 \\
\hline Medium (2 to 5) & $45.4(1408)$ & $44.0(2528)$ & 1.47 & (1.25 to 1.70$)$ & 0.000 \\
\hline Low (0 to 1$)$ & $36.0(219)$ & $27.0(824)$ & 1.00 & & \\
\hline Resource Utilization Bands & & & & & \\
\hline
\end{tabular}


Table 2 Continued

\begin{tabular}{|c|c|c|c|c|c|}
\hline & \multicolumn{2}{|c|}{ Onset of mental health utilisation $(\%, \mathrm{~N})$} & \multicolumn{3}{|c|}{ Model 1} \\
\hline & $\begin{array}{l}\text { Physical } \\
\text { Illness } \\
\text { Cohort } \\
(3075)\end{array}$ & $\begin{array}{l}\text { Control } \\
\text { Cohort } \\
(n=4507)\end{array}$ & HR & $95 \% \mathrm{Cl}$ & p Value \\
\hline Very high (4 to 5 ) & $60.1(694)$ & $55.5(485)$ & 1.45 & (1.16 to 1.74$)$ & 0.000 \\
\hline High (3) & $50.4(1859)$ & $47.4(2124)$ & 1.25 & (1.03 to 1.46$)$ & 0.015 \\
\hline Medium (2) & $43.7(379)$ & $41.7(1203)$ & 1.25 & (1.05 to 1.46$)$ & 0.008 \\
\hline Low (0 to 1$)$ & $36.0(143)$ & $27.3(695)$ & 1.00 & & \\
\hline
\end{tabular}

risk of depression among men with hypertension, ${ }^{20}$ others have shown that women who live with PI are at greater risk of MI. ${ }^{8}{ }^{19}$ Part of the lack of clarity in the field is that studies use different definitions of PI and MI, and use different data sources (eg, survey vs administrative data; self-report vs medical records).

\section{Limitations}

The high prevalence of medical service usage for MI in this sample may reflect our definition of usage, which is broader in scope than specific diagnoses like depression or anxiety disorder. Our definition is based on a chart validation study of the specific medical data examined in this study. ${ }^{29}$ The nature of the data limited our ability to examine specific mental health disorders. For example, the Ontario physician fee code structure allows flexibility with respect to what fee code a physician can use for a mental health visit. This can result in a single diagnoses (eg, depression) being assigned to different fee codes. Our results are interpreted with this in mind.

Research suggests that the true prevalence of PI may be underestimated in self-reported survey data, ${ }^{38}$ however, the CCHS sample is representative of the Canadian population. The study and its findings are restricted to respondents in Ontario and, therefore, are only generalisable to the Ontario population. We restricted our analyses to definitions of PI diagnoses and MI usage from validated registries. Future research might consider other chronic conditions to understand gender differences in onset of usage of medical services for MI, with the latter clearly defined with respect to diagnoses.

Ethnicity is a complicating factor in this field of research. Under-sampling of ethnic groups in the CCHS limited our ability to explore MI by ethnic groupings, as we were only able to look at White versus others and 10-year-recent immigrants. This area of research would benefit from analyses that explore gender differences among those with and without PI by ethnicity.

In the administrative data, the physician fee codes do not capture alternate payment plans. As a result, physicians in community health centres are absent from the data, but non-fee-for-service usage represents a small minority of primary care visits and very few specialists visits (less than $6 \%$ ). ${ }^{39}$

It is possible that increased access to a physician to treat a chronic physical health condition (eg, who have regular contact with their family doctor) may afford a person increased opportunities to consult on comorbid health conditions like MI. If this were the case, then higher usage of medical services for MI might reflect different consulting patterns between the PI and control groups rather than the impact of PI itself. While this is possible, we know that the control group itself is not entirely free of chronic illness (even though we adjust for multiple health comorbidities using ACGs/RUBs and restriction of activities). Additional research is necessary to untangle the relationship between PI and usage of services for MI.

\section{CONCLUSIONS}

Understanding pathways from PI to MI medical service usage is important for health interventions. For example, Goldberg ${ }^{40}$ highlights three ways that chronic PI can lead to depression. First, people with multiple pains associated with PI are at higher risk for depression. For example, Dworkin et $a l^{15}$ found that primary care patients with a single pain were not at increased risk, but those with three or more were five times more likely to experience depression. Pain itself can cause emotional distress and poor sleep. ${ }^{16}$ Moreover, the frequent report of pain might itself be a signal for depression. Second, adults with PI may develop a disability which can bring on depression for those who were healthy before onset of the PI. ${ }^{17}$ Third, physical changes associated with some diseases can increase the allostatic

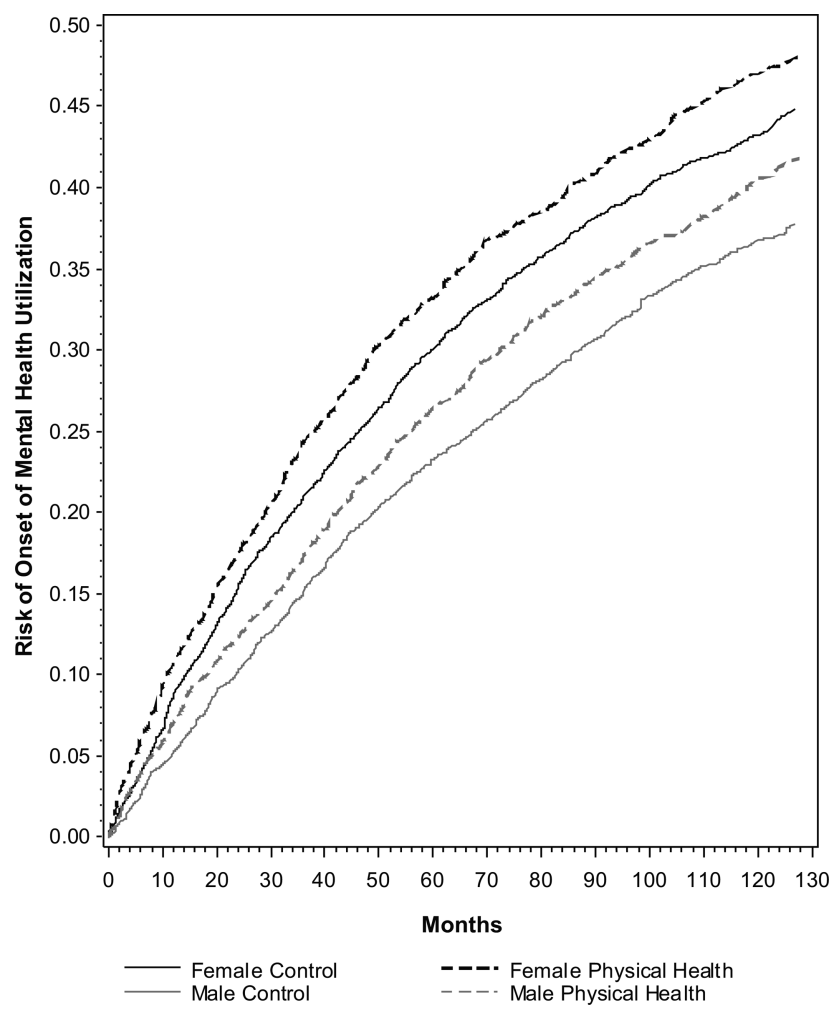

Figure 1 Probability of onset of Mental Health Utilisation (2001-2011) by gender and cohort. 
Table 3 Adjusted HRs for onset of mental health utilisation for gender and cohort by physical illness conditions $(n=17050)$

\begin{tabular}{|c|c|c|c|c|c|c|c|c|c|c|c|c|}
\hline & \multicolumn{3}{|c|}{ Hypertension $(n=3763)$} & \multicolumn{3}{|c|}{ COPD $(n=1.393)$} & \multicolumn{3}{|c|}{ Diabetes $(n=1075)$} & \multicolumn{3}{|c|}{ Asthma(n=2045) } \\
\hline & HR & $95 \% \mathrm{Cl}$ & $p$ Value & HR & $95 \% \mathrm{Cl}$ & p Value & HR & $95 \% \mathrm{Cl}$ & p Value & HR & $95 \% \mathrm{Cl}$ & $p$ Value \\
\hline Female & 1.26 & (1.16 to 1.37 ) & 0.001 & 1.27 & (1.16 to 1.38$)$ & 0.001 & 1.28 & (1.17 to 1.34$)$ & 0.001 & 1.29 & 1.18 to 1.40 & 0.001 \\
\hline PI cohort & 1.16 & (1.04 to 1.29$)$ & 0.01 & 1.19 & (1.01 to 1.37 ) & 0.05 & 0.96 & (0.81 to 1.12 ) & 0.653 & 1.16 & 1.04 to 1.28 & 0.01 \\
\hline
\end{tabular}

load on the patient and heighten risk of depression. ${ }^{18}$ In fact, Verhaak $e t a l^{7}$ suggest that the negative characteristics of the disease throughout its life course, whether progressive or episodic, and other stressful consequences, such as reduced physical abilities, pain, changes in physical appearance, can be strong contributors to developing mental illness. Disability related to chronic illnesses like COPD can include fatigue, shortness of breath, pain, and reduced ability to function normally, and can affect mental health. With this in mind, it is reasonable to assume that the mechanisms that explain the association between chronic disease and mental illness will differ by the type of illness; an important consideration for clinicians helping their patients adapt to the changes brought on by chronic illness.

While studies have found that 'prolonged episode' and 'increased incidence' heighten major depression in people who have medical conditions, we lack knowledge of these pathways in relation to gendered experiences of illness. Further research with an eye to gender analysis and focus on onset of mental illness in cohorts with and without chronic health problems is necessary to understand the types of disparities and inequalities that individuals experience, and to guide health system changes surrounding healthcare quality, delivery and public health policy.

\section{What is already known?}

- Women, by contrast with men, are more likely to seek medical services for mental illness.

- People with a pre-existing chronic physical illness are more likely to use medical services for mental illness.

- Current evidence on gender differences in onset of usage of medical services for mental illness for those with and without physical illness is not definitive.

\section{What this study adds?}

- Findings from this study suggest that women with physical illness were at greatest risk of using medical services for mental illness followed by women without physical illness, men with physical illness and men without physical illness.

- Within any 3-year window, women with physical illness used medical services for mental illness 6.4 months earlier than men.

Acknowledgements This study was supported by the Centre for Research on Inner City Health (CRICH) and the Institute for Clinical Evaluative Sciences (ICES). CRICH is part of the Keenan Research Centre in the Li Ka Shing Knowledge Institute of St. Michael's Hospital. ICES is funded by an annual grant from the Ontario Ministry of Health and Long-Term Care (MOHLTC). The opinions, results and conclusions reported in this paper are those of the authors and are independent from the funding sources. No endorsement by CRICH, ICES or the Ontario MOHLTC is intended or should be inferred.

Contributors FIM, RM and KLWS were responsible for data analysis with intellectual contribution from RHG and JRD. FIM and GF drafted the article. All authors contributed to the conception and design of the paper, interpretation of data, critical revisions contributing to the intellectual content and approval of the final version of the manuscript.

Funding This research was supported by the Social Sciences and Humanities Research Council of Canada, Standard Research Grant No. 410-2009-1894.

Competing interests None.

Ethics approval St. Michael's Hospital Ethics Review Board and Sunnybrook Health Sciences Research Ethics Board.

Provenance and peer review Not commissioned; externally peer reviewed.

Data sharing statement The data housed at the Institute for Clinical Evaluative Sciences (ICES) is available to ICES scientists and those working in collaboration with an ICES scientist through several hubs across Ontario.

Open Access This is an Open Access article distributed in accordance with the Creative Commons Attribution Non Commercial (CC BY-NC 3.0) license, which permits others to distribute, remix, adapt, build upon this work non-commercially, and license their derivative works on different terms, provided the original work is properly cited and the use is non-commercial. See: http://creativecommons.org/ licenses/by-nc/3.0/

\section{REFERENCES}

1 The Power of Prevention. Chronic disease ... the public health challenge of the 21st century. Atlanta: Centers for Disease Control and Prevention, 2009.

2 Chronic Disease - A Public Health Issue. Canadian Coalition for Public Health in the 21st Century, 2005.

3 Broemeling A-M, Watson DE, Prebtani F. Population Patterns of Chronic Health Conditions, Co-morbidity and Healthcare Use in Canada: Implications for Policy and Practice. Healthc Q 2008;11:70-6.

4 Scott KM, Oakley Browne MA, McGee MA, et al. Mental-physical comorbidity in Te Rau Hinengaro: the New Zealand Mental Health Survey. Aust N Z J Psychiatry 2006; 40:882-8

5 Filipcic I, Popovic-Grle S, Marcinko D, et al. Screening for depression disorders in patients with chronic somatic illness. Coll Antropol 2007;31:139-43.

6 Katon WJ. Clinical and health services relationships between major depression, depressive symptoms, and general medical illness. Biol Psychiatry 2003;54:216-26.

7 Verhaak PF, Heijmans MJ, Peters L, et al. Chronic disease and mental disorder. Soc Sci Med 2005;60:789-97.

8 Patten SB, Williams JV. Chronic obstructive lung diseases and prevalence of mood, anxiety, and substance-use disorders in a large population sample. Psychosomatics 2007:48:496-501.

9 Patten SB, Williams JV, Lavorato DH, et al. Major depression as a risk factor for chronic disease incidence: longitudinal analyses in a general population cohort. Gen Hosp Psychiatry 2008;30:407-13.

10 Hsu YM, Su LT, Chang HM, et al. Diabetes mellitus and risk of subsequent depression: a longitudinal study. Int J Nurs Stud 2012;49:437-44.

11 Zhang MW, Ho RC, Cheung MW, et al. Prevalence of depressive symptoms in patients with chronic obstructive pulmonary disease: a systematic review, meta-analysis and meta-regression. Gen Hosp Psychiatry 2011;33:217-23.

12 de Miguel DJ, Hernandez BV, Puente ML, et al. Psychiatric comorbidity in asthma patients. Associated factors. J Asthma 2011:48:253-8.

13 Patten SB. An analysis of data from two general health surveys found that increased incidence and duration contributed to elevated prevalence of major depression in persons with chronic medical conditions. J Clin Epidemiol 2005;58:184-9.

14 van den Bemt $\mathrm{L}$, Schermer $\mathrm{T}$, Bor $\mathrm{H}$, et al. The risk for depression comorbidity in patients with COPD. Chest 2009;135:108-14. 
15 Dworkin SF, Von Korff MM, LeResche L. Multiple pains and psychiatric disturbance. An epidemiologic investigation. Arch Gen Psychiatry 1990;47:239-44.

16 Von Korff MM, Simon G. The relationship between pain and depression. $\mathrm{Br} \mathrm{J}$ Psychiatry Supp/ 1996;(30):101-8.

17 Prince MJ, Harwood RH, Blizard RA, et al. Impairment, disability and handicap as risk factors for depression in old age. The Gospel Oak Project V. Psychol Med 1997;27:311-21.

18 Rittner HL, Brack A, Stein C. Pro-algesic versus analgesic actions of immune cells. Curr Opin Anaesthesiol 2003;16:527-33.

19 Schneider C, Jick SS, Bothner U, et al. COPD and the risk of depression. Chest 2010;137:341-7.

20 Patten SB. Long-term medical conditions and major depression in a Canadian population study at waves 1 and 2. J Affect Disord 2001;63:35-41.

21 Ontario Ministry of Health and Long Term Care. Ontario Health Insurance (OHIP)Ministry Programs. Ontario Ministry of Health and Long Term Care website. 6-5-2011.

22 Matheson Fl, Smith KL, Moineddin R, et al. Mental health status and gender as risk factors for onset of physical illness over 10 years. J Epidemiol Community Health 2014:68:64-70.

23 Health Statistics Division and Special Surveys Division. Canadian Community Health Survey (CCHS) cycle 1.1 derived variable (DV) specifications. Ottawa: Statistics Canada, 2003.

24 Gershon AS, Wang C, Guan J, et al. Identifying patients with physician-diagnosed asthma in health administrative databases. Can Respir J 2009;16:183-8.

25 Gershon AS, Wang C, Guan J, et al. Identifying Individuals with Physcian Diagnosed COPD in Health Administrative Databases. J COPD 2009;6:388-94.

26 Tu K, Campbell NRC, Chen Z-L, et al. Accuracy of administrative databases in identifying patients with hypertension. Open Med 2007;1:e18-26.

27 Hux JE, Ivis F, Flintoft V, et al. Diabetes in Ontario: determination of prevalence and incidence using a validated administrative data algorithm. Diabetes Care 2002;25:512-6.

28 Kessler RC, Andrews G, Mroczek D, et al. The World Health Organization Composite International Diagnostic Interview short-form (CIDI-SF). Int J Methods Psychiatr Res 1998;7:171-85.
29 Steele LS, Glazier RH, Lin E, et al. Using administrative data to measure ambulatory mental health service provision in primary care. Medical Care 2004;42:960-5.

30 Ontario Ministry of Health and Long Term Care. Schedule of benefits for physician services under the Health Insurance Act. Ontario Ministry of Health and Long Term Care website. 1-9-2011. Toronto, ON: Ontario Ministry of Health and Long Term Care, 26-9-2011.

31 White $\mathrm{HL}, \mathrm{O}^{\prime} \mathrm{Campo} \mathrm{P}$, Moineddin $\mathrm{R}$, et al. Modeling the cumulative effects of social exposures on health: moving beyond disease-specific models. Int J Environ Res Public Health 2013;10:1186-201.

32 Matheson $\mathrm{Fl}$, White $\mathrm{HL}$, Moineddin $\mathrm{R}$, et al. Neighbourhood chronic stress and gender inequalities in hypertension among Canadian adults: a multilevel analysis. J Epidemiol Community Health 2010;64:705-13.

33 Reid R, MacWilliam L, Roos NP, et al. Measuring Morbidity in Populations: Performance of the Johns Hopkins Adjusted Clinical Group (ACG) Case-Mix Adjustment System in Manitoba. University of Manitoba, Manitoba Centre for Health Policy and Evaluation, 1999.

34 Statistics Canada. The Research Data Centres Program-Data sets. Bootvar. Statistics Canada website. 14-7-2011.

35 Wells KB, Golding JM, Burnam MA. Psychiatric disorder in a sample of the general population with and without chronic medical conditions. Am J Psychiatry 1988;145:976-81.

36 Baune BT, Adrian I, Jacobi F. Medical disorders affect health outcome and general functioning depending on comorbid major depression in the general population. J Psychosom Res 2007;62:109-18.

37 Mackenzie CS, Gekoski WL, Knox VJ. Age, gender, and the underutilization of mental health services: The influence of help-seeking attitudes. Aging Mental Health 2006;10:574-82.

38 Health Canada. Diabetes in Canada: national statistics and opportunities for improved surveillance, prevention and control. H49-121/1999. Ottawa: Minister of Public Works and Government Services, 1999.

39 Chan B. Atlas Reports: Supply of Physicians' Services in Ontario. Toronto: Institute for Clinical Evaluative Sciences, 1999.

40 Goldberg D. The detection and treatment of depression in the physically ill. World Psychiatry 2010;9:16-20. 